\title{
The influence of action learning on student perception and performance *
}

\author{
B Stappenbelt ${ }^{+}$ \\ School of Mechanical, Materials and Mechatronic Engineering, University of Wollongong, NSW
}

\begin{abstract}
SUMMARY: To more closely align engineering graduate attributes with the demands of industry and governing bodies, there needs to be more explicit educational focus on nurturing abilities related to solving complex, ill-defined engineering problems; communication; teamwork and leadership; and the capacity to undertake life-long learning. A deeper student approach to learning in a problem environment more closely resembling that encountered in engineering practise needs to be encouraged. Action learning fundamentally supports such a deep approach to learning, and is designed to operate within the context of a real and complex project. Action learning facilitates the development of autonomous learners, particularly when the set is gradually allowed to move from a hierarchical to cooperative and eventually a self-directed mode of operation. In the present action learning implementation, four action learning sets were conducted over three years. The sets consisted of students involved in undergraduate engineering research project work. The concurrent study investigated the influence of the action learning environment on student approaches to learning, and any accompanying academic, learning and personal benefits realised. The influence of preferred learning styles on set function and student adoption of the action learning process were also examined. The action learning environment implemented had a positive effect on student academic performance, their ability to cope with the stresses associated with conducting a research project, the depth of learning, the development of autonomous learners and student perception of the research project experience.
\end{abstract}

\section{1}

INTRODUCTION

Revans (1983), largely acknowledged as the founder of action learning (McGill \& Beaty, 2002), described the process of learning in the terms of the reflective inquiry process, where learning is the sum total of attaining programmed knowledge and questioning of current insight. Marquardt (1999) added a third element, reflection, to this model of learning to emphasise its importance. The reflection component of the learning model is where information is recalled, dismantled and reorganised in an attempt to gain further understanding. When considering the facilitation of learning how to solve complex and ill-defined problems, educational methods focusing on the delivery of programmed knowledge alone are clearly insufficient. Programmed knowledge or access to this knowledge is a required pre- or corequisite, however, questioning and reflection are also integral to achieving this higher level learning.

\footnotetext{
* Paper D09-068 submitted 23/07/09; accepted for publication after review and revision 3/02/10.

+ Corresponding author Dr Brad Stappenbelt can be contacted atbrads@uow.edu.au.
}

Action learning is a group-based educational strategy that facilitates individual learning through engagement with group members in the solution of current, real and complex problems. The process of action learning occurs in a group called a set. Widespread current practise is to use sets of between four and seven participants (Beaty, 2003). Sets may be led by a set adviser or facilitator, or they may be self-facilitating. Set meetings are conducted regularly throughout the duration of the problem or project of interest to set members. This problem or project may be individual, group or organisation dictated; however, it must be a real problem with which the set member is currently engaged. Also, the problem must be sufficiently complex so that it cannot be readily solved through direct application of programmed knowledge. Throughout the duration of the problem or project, set members follow the action learning cycle.

The action learning cycle consists of four distinct phases through which the individual learner within the set continually progresses. These consist of an action phase, reflection upon that experience, theorising based upon the reflective analysis of 
prior experience in the action phase, and eventually a planning phase, where subsequent actions are determined in the form of a list of action points (Beaty, 2003). Within the set meetings, the phases of reflection, theorising and planning undertaken by individual set members are supported by the other set members. Between set meetings the learner works through the action plan in the context of the real and complex problem of interest. The action phase therefore produces experience of direct relevance to further understanding and further learning related to the problem. Action learning thus provides a formalised educational structure to facilitate experiential learning. It allows the learner to move through the experience, reflection, generalisation and testing of these generalisations as described by the Kolb experiential learning cycle (McGill \& Beaty, 2002; Kolb \& Kolb, 2005) in a structured manner supported by the experiences, questioning and insights of others.

An action learning set is not a team, even if a single problem or project is shared among the set members. The group dynamics associated with teams are very different. Teams have well-defined group objectives and all members of the team work to complete associated tasks for the benefit of the team. Plans are generally discussed and agreed upon by the team as a whole and there is no emphasis on individual learning. In the action learning set, the set members have individual objectives, and the other members work to support the learning and actions of these individuals. This does not mean, however, that action learning set members cannot also concurrently function as team members. The two modes of group interaction, however, must be clearly delineated. At the other extreme in the continuum of group based education, it must be noted that a set is not merely a support or counselling group (McGill \& Beaty, 2002). However, it is well documented that empathy is central to the action learning process (McGill \& Beaty, 2002; Hughes \& Bourner, 2005). One commonly employed method for enhancing empathy within the set is the use of a checking-in process as discussed in Hughes \& Bourner (2005) or use of a similar warm-up exercise (McGill \& Beaty, 2002). Hughes \& Bourner (2005) believe that the use of the check-in is essential to the action learning method, but the form of this process is flexible, and may be defined and refined by the group. The check-in process may simply take the form of sharing each set members significant personal developments since the last set meeting or consist of a more structured exercise. In addition to serving as a means to enhance empathy and appreciating the personal context of other set members, the checking-in process also acts as a means to enable the relinquishing of external professional roles. This is necessary, among other reasons, to reduce any formal hierarchical arrangements that exist between set members in their professional capacities.

\section{ACTION LEARNING IN THE CONTEXT OF HIGHER EDUCATION}

Traditional instruction in higher education institutions, commonly based on lectures and tutorials, tends to be didactic, hierarchic, teacher controlled and dependent, with passive student involvement (McGill \& Beaty, 2002). This is of course not always the case, but most higher education tends to be teacher-centred. Action learning is student-centred learning. It takes into account the many different levels of student knowledge, skills, motivation, experiences and the like, rather than the traditional teacher-centred approaches that essentially treat students identically. In a learnercentred approach to engineering education, the learners' needs guide the method of instruction (Felder \& Brent, 2005). This approach involves the establishment of "environments that pay careful attention to the knowledge, skills, attitudes, and beliefs that learners bring to the educational setting" (National Research Council, 1999). Traditional methods tend to focus on passive instruction rather than active student involvement. Dale (1969), with reference to the cone of experience, clearly demonstrated the positive link between the retention of knowledge and active learner participation. Direct purposeful experiences, such as those resulting from an action plan in an action learning framework, rated most educationally beneficial to the learner in this context. Action learning facilitates the creation of autonomous learners in contrast to traditional methods, where instruction remains hierarchical throughout. Under many traditional educational approaches, the student is also not likely to have acquired the means or confidence to move beyond the hierarchical mode upon completion of their study (McGill \& Beaty, 2002). This is clearly an undesirable situation for higher education institutions and their graduates.

There exists increasing pressure on higher education institutions to provide instructional methods, content and graduates with attributes more closely aligned with the needs of industry ( $\mathrm{O}^{\prime}$ Brian \& Hart, 1999). Late last century saw growing support for major reform of engineering curricula to include "integrated and experiential activities and early exposure to engineering" and more explicit focus on "skills such as problem-solving, communication, team and leadership, and life-long learning" (Fink et $\mathrm{al}, 2005)$. The numerous reports cited in the work by Fink et al (2005) called for these educational changes "to educate students for life by helping them learn how to learn". A popular curriculum design that has been adopted in response to this drive is problembased learning. In the problem-based learning model, a case study is designed to reveal to students the required curriculum content progressively under the guidance of a group facilitator. Students are actively involved in the research and investigation 
of the case. The use of problem-based teaching and learning techniques has been demonstrated to improve student perception of the industry relevance of the material taught in the course (Bemold et al, 2000; Dichter, 2001; Dym et al, 2005). There exist many similarities between problem-based and action learning models. Both are based on the experiential learning cycle, incorporating action, reflection, hypothesising and planning. Relative to the problem-based learning structure, however, action learning allows more self-directed learning and is less hierarchically structured. The nature of student involvement in the action phase in problembased learning is contrived, rather than based on real experiences in the action learning process. The sorts of transferable skills developed in an action-based educational approach have been shown to be directly applicable to the needs of industry. The study by O'Brian \& Hart (1999), for example, demonstrated the utility of action learning in meeting the graduate attribute expectations of employers.

The study of Pedler et al (2005) regarding the form and prevalence of action learning in higher education use, revealed the following general agreement regarding the key features of action learning:

1. Action learning sets consist of approximately six people.

2. The action phase must be associated with real tasks or problems.

3. Learning comes from reflection on actions taken.

4. Tasks or problems are individual, rather than collective.

5. Tasks or problems are chosen independently by individuals.

6. Questioning is the main way to help participants proceed with their tasks or problems.

7. Action learning sets are part of an existing program.

8. Action learning set facilitators are used.

9. Some taught elements are included in the action learning process.

10. The action learning is linked to a qualification.

Features 2, 3 and 6 are classic action learning features as originally defined by Revans (1983). Points 7, 8, 9 and 10 are features of action learning that would appear to be attributable to the higher education context and its specific requirements. The key features of action learning in higher education 1 , 4, 5 and 8 depart somewhat from Revan's original action learning model, but are widespread in current higher education practice of action learning (Pedler et al, 2005).

The surveys of Pedler et al (2005) showed growth in the usage of action learning in higher education is very slow relative to the general uptake of action learning in government organisations and business. Most practitioners of action learning in higher education began using it more than 10 years ago, and of these $42 \%$ testified to a decrease or no change in usage compared to when they first begun. The factors limiting the adoption of action learning in higher education were reported to be the lack of theoretical input in the action learning process, the resource rich nature of action learning and the overcomplicated or ill-defined nature of action learning.

One of the defining characteristics of higher education is the maturity of the students. The adult learner tends to be more self-directed, their experience makes them valuable resources to one another, adults approach learning with a task or problem-centred orientation, they are more motivated by internal rather than external factors and role models can be very effective in triggering readiness to learn (Marquardt \& Waddill, 2004). These learner characteristics are well suited to an action learning environment. A number of adult learning schools or metatheories exist with distinctive approaches and perspectives on learning. These include cognitivist, behaviourist, humanist, social learning and constructivist theories. The study by Marquardt \& Waddill (2004) demonstrated that the action learning process satisfies the vital conditions necessary for learning established by each of these adult learning schools. They assert that the high level and quality of learning in an action learning environment is due to the ability of the action learning process to utilise a wide range of these learning theories.

Central to the discussion surrounding action learning is the concept of student approaches to learning. The relationship between student learning and the material to be learnt may be described in terms of a continuum with surface and deep approaches at the extremes (Ramsden, 2003). The surface approach is focused on task requirements and discrete elements of the material necessary to accomplish the task. It does not tend to consider and reflect upon the integration of these parts and an understanding of the whole. The deep approach to student learning, at the other end of the continuum, is interested in the understanding of concepts and gaining new insights. Reflection is fundamental to the deep approach to learning as new knowledge is related to previous knowledge, theoretical ideas and prior experiences. Evident in the presently overcrowded engineering curriculum is the tendency for students to favour a surface achieving approach to their studies. Ramsden (2003) stated that there is "evidence that the overloaded content of engineering courses leads to many engineering students taking an instrumental approach to their studies. This is marked by a motivation to pass exams in order to obtain a degree rather than to being driven by an interest in learning." It is widely recognised that a deeper student approach to learning is required to improve education to meet industry requirements of graduates (O'Brian \& Hart, 1999). Since deeper learning approaches require the integration of experience, reflection, formation of 
links with prior knowledge and theorising, it is clear that action learning sets fundamentally support a deep approach to student learning (McGill \& Beaty, 2002). Establishing action learning environments has been shown to encourage students toward such a deeper learning approach (Wilson \& Fowler, 2005).

In a higher education setting it is likely that the action learning sets formed for a particular unit of study within the curriculum will be facilitated by a member of the academic staff. This tutor will act as the set facilitator and often also as a readily accessible content expert in a particular field. With reference to the three modes of facilitation outlined by Heron (as discussed in McGill \& Beaty, 2002), such a set facilitator would begin as a hierarchical facilitator and ideally move the set gradually to an autonomous mode of facilitation. The hierarchical mode is a necessary beginning in this context due to the dependent nature of the relationship of the set participants to the facilitator and the set members' relative inexperience with the functioning of an action learning set. Unlike many traditional educational frameworks, however, the set should not remain hierarchical; instead the facilitator should aim to share control and allow the set to become increasingly self-directing. This is known as the cooperative mode of facilitation. Ideally, the set will continue this trend until it is functioning entirely in the autonomous mode, where each participant is entirely self-governing and the set becomes completely self-directed. This extreme, however, is not likely to be a realistic mode of action learning set facilitation when the sets are part of a unit of higher education study as the facilitator is likely to retain a powerful and influential position in the set due to their evaluative role.

Traditional learning environments tend to favour passive, intuitive and verbal learning styles (Felder \& Silverman, 1988). Engineering students have been shown to generally possess preferences for active rather than reflective learning, sensory rather than intuitive, visual over verbal and sequential rather than global learning (Felder \& Brent, 2005). This represents a mismatch between learning and commonly adopted teaching styles. These mismatches can lead to poorer learning as indicated by student academic performance of various student groups in the study by Livesey \& Stappenbelt (2006). The study by Freire (1972) also suggested that the traditional model of instruction, utilising lectures and other chalk and talk methods to passive students, is not only ineffective but also disadvantages some student groups whose learning styles and approach to problems are highly valued in the engineering profession. The research by Bernold et al (2007) is in general agreement with this finding, stating that those with learning styles that deviate from traditional teaching methods tend to leave the more traditionally taught lecture environment. Providing first-year engineering students with an active learning environment, in addition to faculty mentoring and discipline-specific advice, has been demonstrated to have a positive effect on the retention rates of female engineering students and other minority groups (Hoit \& Ohland, 1998; Webster \& Dee, 1998). Student preference for particular learning styles can give rise to unequal distribution of an individual's resources to the various stages of the learning cycle. The action learning framework encourages set members to place equal weight on the time and effort dedicated to each of the elements involved in learning (McGill \& Beaty, 2002).

From an educational perspective, there are many motivators for implementing an action learning environment in the undergraduate curriculum. Among these is the case for preparing students for lifelong learning. It is one of the primary functions of higher education to teach students how to learn and how to continue lifelong learning. Engineers Australia professional competency PE 3.6 states that undergraduate engineering programs should prepare students to recognise the need for lifelong learning and to develop the capacity to engage in it (Engineers Australia, 2008). In an action learning environment, students are encouraged to become autonomous learners. This responsibility requires that students develop an understanding of personal learning strategies and approaches, acquiring knowledge from a variety of sources and recognition of personal limitations. As stated by the Department of Education, Science and Training (2006), higher education should aim to move beyond simply preparing graduates for employment in their chosen field and contribute to the development of graduates with the ability to continually question current practise and beliefs to the benefit of society. Such a deeper approach to learning, the search for meaning in experience and knowledge is again integral to the action learning process.

\section{APPLICATION OF ACTION LEARNING TO UNDERGRADUATE STUDENT RESEARCH PROJECTS}

The context of the present action learning implementation was the penultimate- and final-year research project units in mechanical engineering. Four action learning sets were conducted over three years. The action learning sets consisted of students wishing to undertake experimental or numerical research in the broad field of flowstructure interaction. The overall effectiveness of the action learning model implemented was examined in terms of student perception of learning and academic performance. From a pedagogical (or more correctly an andragogical) perspective, preferred learning styles, student approaches to learning, and their influence on the acceptance and functioning of an action learning set by individual members were investigated. 
Since this paper deals with action learning in a research project situation, the widespread use of the terms action learning and action research should be addressed. Action learning and action research are based on the same learning cycle. The distinction appears to manifest in the purpose and outcomes. The intent of action learning is to improve learner understanding, the action researcher, however, aims to understand and implement change simultaneously (Dick, 1997). In the specific context of the undergraduate research project, the set is implemented in a manner more closely resembling action learning than action research. Set members bring research projects to the set, but the intended outcome, and the focus of the process is improved individual understanding of the problem and associated knowledge. Modern implementation of the action learning and research methods overlap significantly and it is argued that a distinction between the two is not worth preserving (Dick, 1997; Krogh, 2001).

A total of 20 students participated in the research project action learning sets over three years. The number of participants in each set varied between four and seven. Unlike the action learning sets described in David (2006), set membership was not compulsory. Those who were opposed to the action learning concept were not persuaded to join the set. The sets met weekly for meetings of three hours duration. All students were working on flow-structure interaction projects and therefore often needed to function as a team as well as an action learning set. Part of the three-hour gathering was therefore often dedicated to team issues. This component of the meeting was clearly delineated from the action learning set meeting. As was the case in the reports by Sankaran et al (2006) and David (2006), set members were prepared for the action learning process through a short tutorial. An understanding of the process and the aims of the action learning set were considered integral to the adoption and successful functioning of the method. The programmed knowledge component of learning was very familiar for all participants in the set. The questioning insight component was a relatively underdeveloped skill in most set members, consistent with the case study observations by David (2006).

Prior to commencement of the action learning set meetings, two surveys collecting information on preferred learning styles and student approach to learning were administered. Specifically these were the Index of Learning Styles (ILS) survey (Felder \& Silverman, 1988) and the Study Process Questionnaire (SPQ) (Biggs, 1987). At the conclusion of the student projects and the accompanying set meetings, student feedback was sought regarding their perceptions of the action learning experience. The SPQ was also re-administered with the instruction to consider their approach to learning during their research project only.

\section{4}

\section{RESULTS AND DISCUSSION}

In the process of implementing an action learning environment for undergraduate research projects, several key practical observations regarding set facilitation were made. These are discussed briefly prior to examining the results of the surveys administered.

The checking-in stage of the set meetings proved difficult to shape in order to address the multiple aims of developing an appreciation of the context of other set member's projects, developing empathy between set members and relinquishing of external roles. After attempts at some more formal exercises (as described in McGill \& Beaty, 2002), the groups eventually agreed that an informal drink (ie. coffee, tea, etc.) was the most effective warm-up. This was generally combined with personal discussions between set members. The checking-in stage was especially useful in the early stages of set development when the traditional teacher-students hierarchy needed to be addressed.

At the commencement of each set, it was necessary to allow the set to establish their own ground rules upon which interaction in the meetings was governed. The rules covered issues such as listening to others when they are speaking, maintaining non-judgmental attitudes, attendance at meetings and participation in the process. With regard to participation in particular, the sets were encouraged to make each student accountable to the other set members for their participation in the meetings. With fewer set members, sets do not function as effectively and it was agreed upon within each set that this was not in the best academic interest of any group member. In this manner, the sets learnt to self-regulate, reducing the need for facilitator intervention.

Regarding the relationship between set members, trust and accountability within the group needs to be established early. Without trust and a sense of confidentiality, several personal issues affecting academic performance raised throughout the projects undertaken would not have surfaced. This could potentially have minimised the effectiveness of the sets to empower individual learners to proactively deal with the situation. Without trust between set members, the sets could potentially be an additional source of stress for the students rather than an avenue to search for solutions.

Since the aim of set facilitation is to move toward autonomous facilitation, the set facilitator must avoid acting as the authority. This was difficult to establish in the context of the inherent studentteacher relationships. The set facilitator is necessarily the content expert in the field of research undertaken by the students. It was therefore tempting to fill in the blanks whenever this was requested by the students. A much better approach for student learning, however, was to respond with questions 
that guide the student to forming an action list, which would allow them to discover the answers independently. This does not, however, mean that student misconceptions (especially early in the projects) were permitted to propagate.

When the facilitator tends to lead the majority of the discussion, it is necessary for the set facilitator to leave the room. Once the set members understand the process, the need for the facilitator should decrease. Five to ten minutes outside the room rapidly encouraged students to re-engage with the process. The occasional moderation, correction or improved explanation by the facilitator was all that was required toward the end of the projects. Students in each set quickly learnt the sort of questions they needed to ask one another to assist that person to reach the next step or identify a new direction in their projects.

Three of the four action learning phases were explicitly covered within the set meetings. Set members rapidly understood the need to reflect, theorise and then plan their next action phase as part of the meeting process, but significant facilitation was required, especially in the early stages, to ensure adequate attention and importance was placed on each phase. Due to individual student learning style preferences, there exists a tendency for students to focus predominantly on their favoured phases of the action learning cycle. This is of course counterproductive in terms of the quality of learning and project progress using the action learning process.
Four surveys were conducted, two at the commencement and two at the conclusion of the projects. Some of the observations made throughout this trial of action learning are discussed in light of the data collected. The resulting conclusions, based on the necessarily limited data sample, are supported by prior studies and serve to illustrate some of the useful qualitative observations made. The primary results of interest were those associated with the student perception survey presented in tables 1 and 2 . The student perception survey response range for questions one to seven was 1 (strongly disagree) to 5 (strongly agree). The neutral response was 3. Questions eight to 11 related to the four action learning phases (ie. action, reflection, theorising and planning). In interpreting these results, it is pertinent to know that most students involved in the present study were well acquainted with oneto-one supervision through prior research projects. In this situation, the student generally meets with the supervisor weekly or fortnightly to provide an update on the project and to receive guidance regarding project direction.

According to the student perception survey conducted at the conclusion of the research projects, all students strongly agreed that the action learning set meetings were useful. All students also strongly agreed that they preferred this method of project guidance to the more commonly employed oneto-one supervisory style. Another benefit of the regular set meetings was that the set had the effect of

Table 1: $\quad$ End of project student perception survey part a $(n=20)$.

\begin{tabular}{|c|c|c|c|c|c|c|c|}
\hline Statement & Strongly disagree & Disagree & Unsure & Agree & Strongly agree & Mean & SD \\
\hline 1 & $0 \%$ & $0 \%$ & $0 \%$ & $10 \%$ & $90 \%$ & 4.90 & 0.31 \\
\hline 2 & $0 \%$ & $0 \%$ & $0 \%$ & $5 \%$ & $95 \%$ & 4.95 & 0.22 \\
\hline 3 & $0 \%$ & $0 \%$ & $20 \%$ & $40 \%$ & $40 \%$ & 4.20 & 0.77 \\
\hline 4 & $0 \%$ & $0 \%$ & $5 \%$ & $25 \%$ & $70 \%$ & 4.65 & 0.59 \\
\hline 5 & $0 \%$ & $5 \%$ & $20 \%$ & $30 \%$ & $45 \%$ & 4.15 & 0.93 \\
\hline 6 & $0 \%$ & $0 \%$ & $10 \%$ & $20 \%$ & $70 \%$ & 4.60 & 0.68 \\
\hline 7 & $0 \%$ & $0 \%$ & $5 \%$ & $5 \%$ & $90 \%$ & 4.85 & 0.49 \\
\hline
\end{tabular}

1. The action learning set meetings were a useful part of the unit; 2 . I prefer the action learning framework to one-to-one supervision; 3. Action learning has improved my academic performance; 4 . Action learning has given me a deeper understanding of my research topic; 5 . I felt in charge of my project direction and progress; 6 . The meetings helped me to quickly gain a sense of competency about my project; 7. Action learning helped to reduce stress associated with the project.

Table 2: $\quad$ End of project student perception survey part $\mathrm{b}(n=20)$.

\begin{tabular}{|c|l|c|l|}
\hline & Question & Mode & Phase \\
\hline 8 & Which phase did you have the most difficulty with? & 4 & Planning \\
\hline 9 & Which phase did you enjoy the most? & 2 & Reflection \\
\hline 10 & Which phase was the most useful? & 2 & Reflection \\
\hline 11 & Which phase did you find the least useful? & 4 & Planning \\
\hline
\end{tabular}


minimising individual student lapses in enthusiasm, motivation and progress. This observation is similar to that described in the account of practice by Sankaran et al (2006). The less hierarchical mode of project supervision created in an action learning environment empowered the students and lent itself to a heightened sense of project ownership (see the result of questions five and six of the student perception survey in table 1). Action learning empowers the learner by facilitating a proactive stance with regard to project direction and progress and any other associated issues. This resulted in an improved sense of competency, and the ability to express the knowledge and understanding gained.

Previous learning style studies have shown that engineering students generally display preferences toward active, sensing, visual and sequential learning (Felder \& Brent, 2005). Table 3 contains the results of the ILS survey for all action learning sets. Each dimension ranges in score from -11 to 11 . A score magnitude between 1 and 3 indicates a slight preference, with a score of 8 or more representing a strong preference for a particular learning style. The mean scores for each dimension indicate that the action learning set members learning style preferences are consistent with previous studies. The action learning set members displayed a strong preference for a visual learning style, and a slight to medium preference for active, sensing and sequential learning. From the student perception survey (table 2 ), the phase of the action learning cycle favoured by the set members was reflection. This phase was also considered most useful by all set members. The action learning framework forces the set members to spend time on each of the experiential learning phases. Since engineering students (and the set members) favour action over reflection, it is not overly surprising that this attention on reflection resulted in improved learning and hence usefulness regarding the successful completion of their projects. The phase most students had difficulty with and also rated as least useful was the planning stage. This difficulty was observed especially throughout the initial meetings where set members clearly struggled to develop a clear list of action points from quite fruitful reflection and theorising. A large amount of variation was observed, however, in the responses to the survey questions in part $b$.

Of interest in the present case study was whether undergraduate research project work in an action learning environment would have a beneficial effect on academic performance as well as the quality of student learning. The discussions conducted in an action learning set are not limited to the technical aspects of the problem. The action learning environment is conducive to surfacing many underlying student performance issues, such as poor information gathering, evaluation and management skills, poor time management and record keeping, personal problems affecting concentration or effort, misconceptions regarding thesis structure, and the like. A noteworthy result of the student perception survey (table 1) was that all students strongly agreed that their perceived stress levels during their projects were reduced as a result of the action learning set meetings. In a typical one-to-one supervisor-student relationship the student works in relative isolation from other students. Implementation of an action learning environment was therefore expected to manifest in improved overall academic performance. An attempt was made to quantify this improvement in performance by comparing student thesis and report marks to their course weighted average mark for both the action learning set members and the control group consisting of the remainder of the enrolled students in the corresponding unit(s). The results of this analysis are presented in table 4 confirming this hypothesis. The t-test for equality of means yields a p-value of 0.001 thus rejecting the null hypothesis that there is no statistically significant difference between the means. Student perception of this improvement prior to the release of marks was that they felt action learning had improved their performance (table 1).

The mean SPQ scores for the action learning set members are presented in table 5. This questionnaire was administered prior to the commencement of

Table 3: $\quad$ Mean learning style preferences $(n=20)$.

\begin{tabular}{|l|c|c|c|}
\hline Dimension & \multicolumn{2}{|c|}{ Mean score } & SD \\
\hline Active/Reflective & 3.25 & (active) & 1.48 \\
\hline Sensing/Intuitive & 3.85 & (sensing) & 2.03 \\
\hline Visual/Verbal & 10.55 & (visual) & 2.63 \\
\hline Sequential/Global & 1.70 & (sequential) & 4.60 \\
\hline
\end{tabular}

Table 4: $\quad$ Mean thesis (or report) and course weighted average marks.

\begin{tabular}{|l|c|}
\hline Group & Mean difference (\%) \\
\hline Action learning set members $(n=20)$ & 4.15 \\
\hline Control group $(n=436)$ & 0.68 \\
\hline
\end{tabular}


Table 5: $\quad$ Study process questionnaire (SPQ) mean responses $(n=20)$.

\begin{tabular}{|l|c|c|c|c|}
\hline Motives and strategies & $\begin{array}{c}\text { Mean score } \\
\text { (pre-project) }\end{array}$ & $\begin{array}{c}\text { Percentile } \\
\text { (pre-project) }\end{array}$ & $\begin{array}{c}\text { Mean score }_{\text {(post-project) }} \\
\text { (prercentile }\end{array}$ & $\begin{array}{c}a \\
\text { (post-project) }\end{array}$ \\
\hline Surface motive (SM) & 25.8 & $81-90$ & 22.8 & $61-70$ \\
\hline Surface strategy (SS) & 25.2 & $71-80$ & 19.7 & $31-40$ \\
\hline Deep motive (DM) & 19.2 & $21-30$ & 23.7 & $61-70$ \\
\hline Deep strategy (DS) & 20.8 & $41-50$ & 25.0 & $71-80$ \\
\hline Achieving motive (AM) & 29.4 & $91-100$ & 29.2 & $91-100$ \\
\hline Achieving strategy (AS) & 21.8 & $61-70$ & 23.6 & $71-80$ \\
\hline Surface approach (SA) & 51.0 & $81-90$ & 42.5 & $31-40$ \\
\hline Deep approach (DA) & 40.0 & $31-40$ & 48.7 & $71-80$ \\
\hline Achieving approach (AA) & 51.2 & $81-90$ & 52.8 & $91-100$ \\
\hline Deep achieving approach (DAA) & 91.2 & $61-70$ & 101.5 & $81-90$ \\
\hline${ }^{a}$ Normative data from Biggs (1987) & \multicolumn{5}{l}{} \\
\hline
\end{tabular}

the research project, reflecting the student's usual approach to study prior to their action learning experience, and post project. The second SPQ was administered with the instruction to consider the approach to learning during their research project only. In light of the normative data available from Biggs (1987), the set members' usual approach to learning displayed a strong achieving orientation. Students adopting this approach will tend to use surface or deep learning when it is in their best interest or when guided toward a particular approach by the teacher. The group tended to favour the surface approach as their general approach to study throughout their degree. The action learning environment encouraged these students to develop a deeper approach. Such a shift toward a deeper student learning approach has previously been demonstrated in a study of the impact of action learning environments on behavioural science students' approach to learning (Wilson \& Fowler, 2005). These changes in approach to learning were clearly evident in the present case study. Students generally felt that at the conclusion of the project they were approaching their learning at a deeper level than would have been achieved without set meetings and the action learning framework (table 1).

In the study by Pedler et al (2005), the primary factors identified limiting the adoption of action learning in higher education were reported as the lack of theoretical input in the action learning process, the resource rich nature of action learning and the overcomplicated or ill-defined nature of action learning. In the present implementation, it was found that the lack of theoretical input throughout the action learning process was readily overcome by using a part of the weekly meeting time in a more formal educational sense, where team issues were discussed and agreed upon theoretical input was supplied. It was found that through the use of action learning sets, student awareness of sources, and their ability and willingness to share theoretical resources was much improved. With regard to the resources required to implement action learning, a room and a whiteboard were all the additional resources required to create an action learning environment for the students' research projects. The supervisory time spent in the action learning sets was less than the combined total of individual project supervision. The principles upon which the action learning process is based are relatively simple. The overly complex recipe-like implementation suggested in some sources is felt to be responsible for the misconception that action learning is overcomplicated or ill-defined in nature.

\section{CONCLUSIONS}

The qualitative study by Jonassen et al (2006), which examined real engineering problems in the context of engineering education, concluded that "because solving well-structured problems in science and engineering classrooms does not readily lead to solving complex, ill-structured workplace problems, engineering programs must support learning to solve complex, ill-structured workplace problems if they are to prepare their graduates for future learning and work". The action learning environment established for undergraduate mechanical engineering student project work in the present study supported the learning of skills required for more than straightforward right-answer problem-solving, rote learning and simplistic approaches to complex situations. The ability to tackle the sort of problems encountered in professional engineering practice is clearly a desirable graduate attribute.

A deeper student approach to learning is required to improve education to meet industry requirements of engineering graduates (O'Brian \& Hart, 1999). Action learning fundamentally supports such a 
deep approach to student learning and is therefore recommended as a highly suitable framework in which to conduct undergraduate research project work. The action learning environment implemented had a positive effect on student performance, their ability to cope with the stresses associated with managing a large research project, the depth of learning, the development of autonomous learners and student perception of the research project experience.

It is interesting to note that the advancement of personalised learning was listed among the 14 most important engineering projects for the future (the "Grand Challenges for Engineering") by a committee selected by the National Academy of Engineering (Butcher, 2008). "Personalised learning - in which instruction is tailored to a student's individual needs - has gained momentum in recent years due to a growing appreciation for individual aptitudes" (Butcher, 2008). The author would like to conclude therefore with an encouragement for engineering educators to trial the student-centred approach of action learning in project-related coursework. As stated by David (2006), "action learning is an approach only truly understood experientially theoretical explanations can give only a partial sense of the approach in practice."

\section{ACKNOWLEDGEMENTS}

The author gratefully acknowledges the participation of the research project students involved in the action learning sets, as well as the learning inspiration contributed by Alexa Zoe Stappenbelt. The guidance provided by Heather Sparrow from Edith Cowan University was also much appreciated.

\section{REFERENCES}

Beaty, L. 2003, “Action Learning, LTSN Generic Centre Continuing professional development series", No. 1.

Bemold, L. E., Bingham, W. L., McDonald, P. H. \& Attia, T. M. 2000, "Influence of Learning Type Oriented Teaching on Academic Success of Engineering Students", Journal of Engineering Education, Vol. 89, No. 1, pp. 191-199.

Bernold, L. E., Spurlin, J. E. \& Anson, C. M. 2007, "Understanding Our Students: A LongitudinalStudy of Success and Failure in Engineering With Implications for Increased Retention", Journal of Engineering Education, Vol. 96, No. 3, pp. 263-274.

Biggs, J. 1987, "Student approaches to learning and studying", Australian Council for Educational Research, Hawthorne, Victoria.

Butcher, D. R. 2008, “21 ${ }^{\text {st }}$ Century's Grand Challenges for Engineering", ASME METoday newsletter, April,
www.asme.org/NewsPublicPolicy/Newsletters/ METoday/Articles/21st_Centurys_Grand.cfm.

Dale, E. 1969, Audiovisual methods in teaching, $3^{\text {rd }}$ editon, Dryden Press, New York.

David, H. 2006, "Action learning for police officers in high crack areas", Action Learning: Research and Practice, Vol. 3, No. 2, pp. 189-196.

Department of Education, Science and Training, 2006, "Higher Education Review Process - Higher Education at the Crossroads: An Overview Paper", www.backingaustraliasfuture.gov.au/publications/ crossroads/default.htm.

Dichter, A.K., 2001, 'Effective Teaching and Learning in Higher Education, with Particular Reference to the Undergraduate Education of Professional Engineers', International Journal of Engineering Education, 17/1, pp. 24-29.

Dick, B. 1997, "Action learning and action research", www.scu.edu.au/schools/gcm/ar/arp/actlear.html.

Dym, C. L., Agogino, A. M., Eris, O., Frey, D. D. \& Leifer, L. J. 2005, “Engineering Design Thinking, Teaching, and Learning", Journal of Engineering Education, Vol. 94, No. 1, pp. 103-120.

Engineers Australia, 2008, "Australian Engineering Competency Standards - Stage 1 Competency Standards for Professional Engineers", www. engineersaustralia.org.au/index.cfm?3D0D4566DEB0-1AC4-F916-8AA936CB7041.

Felder, R. \& Brent, R. 2005, “Understanding student differences", Journal of Engineering Education, Vol. 94, No. 1, pp. 57-72.

Felder, R. \& Silverman, I. 1988, "Learning and Teaching Styles in Engineering Education", Journal of Engineering Education, Vol. 78, No. 7, pp. 674-681.

Fink, L. D., Ambrose, S. \& Wheeler, D. 2005, "Becoming a Professional Engineering Educator: A New Role for a New Era", Journal of Engineering Education, Vol. 95, No. 1, pp. 185-194.

Freire, P. 1972, Pedagogy of the Oppressed, Penguin, New York, NY.

Hoit, M. \& Ohland, M. W. 1998, "The Impact of a Discipline-Based Introduction to Engineering Course on Improving Retention", Journal of Engineering Education, Vol. 87, No. 1, pp. 79-85.

Hughes, M. \& Bourner, T. 2005, “Action learning set meetings: getting started by checking in", Action Learning: Research and Practice, Vol. 2, No. 1, pp. 89-95. 
Jonassen, D., Strobel, J. \& Lee, C. B. 2006, “Everyday problem solving in engineering: lessons for engineering educators", Journal of Engineering Education, Vol. 95, No. 2, pp. 139-151.

Kolb, A. \& Kolb, D. 2005, “The Kolb Learning Style Inventory - version 3.1", Technical Specifications, Experience Based Learning Systems Inc.

Krogh, L. 2001, "Action research as action learning as action research as action learning ... at multiple levels in adult education", Research to reality: putting VET research to work, Australian Vocational Education and Training Research Association, Alexandria, NSW.

Livesey, M. \& Stappenbelt, B. 2006, “Learning style prevalence of engineering students", HERDSA Rekindled Conference, Perth, Australia.

Marquardt, M. 1999, Action learning in action: transforming problems and people for world-class organisational learning, Davies-Black Publishing, Palo Alto.

Marquardt, M. \& Waddill, D. 2004, "The power of learning in action learning: a conceptual analysis of how the five schools of adult learning theories are incorporated within the practice of action learning", Action Learning: Research and Practice, Vol. 1, No. 2, pp. 185-202.

McGill, I. \& Beaty, L. 2002, Action Learning: a guide for professional, management $\mathcal{E}$ educational development, $2^{\text {nd }}$ edition, Kogan Page Ltd, London.
National Research Council, 1999, How People Learn: Brain, Mind, Experience, and School, National Academy Press, Washington, DC.

O'Brian, E. \& Hart, S. 1999, "Action learning: the link between academia and industry", Journal of Educational Research, Vol. 41, No. 1, pp. 77-89.

Pedler, M., Burgoyne J. \& Brook, C. 2005, “What has action learning learned to become", Action Learning: Research and Practice, Vol. 2, No. 1, pp. 49-68.

Ramsden, P. 2003, Learning to teach in higher education, $2^{\text {nd }}$ edition, Routledge Falmer, London.

Revans, R. 1983, ABC of Action Learning, ChartwellBratt, Bromley.

Sankaran, S., Hase, S., Dick, B. \& Davies, A. 2006, "Reflections on developing an offshore, action research/learning-based PhD program", Action Learning: Research and Practice, Vol. 3, No. 2, pp. 197-211.

Webster, T. J. \& Dee, K. C. 1998, “Supplemental Instruction Integrated Into an Introductory Engineering Course", Journal of Engineering Education, Vol. 87, No. 4, pp. 377-383.

Wilson, K. \& Fowler, J. 2005, "Addressing the impact of learning environments on students' approaches to learning: comparing conventional and action learning designs", Assessment and Evaluation in Higher Education, Vol. 30, No. 2, pp. 87-101. 


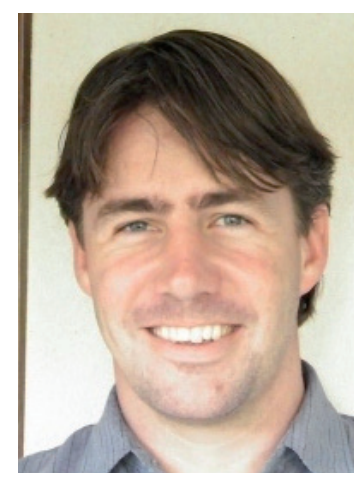

\section{BRAD STAPPENBELT}

Dr Brad Stappenbelt currently works at the School of Mechanical, Materials and Mechatronic Engineering at the University of Wollongong, and with the University of Western Australia in an Adjunct Lecturer position. Brad holds a BEng degree in Mechanical Engineering and $\mathrm{PhD}$ in the Offshore Engineering field. His research interests include engineering pedagogy, flow-structure interaction, vortex-induced vibration, floating structure dynamics and wave energy systems. Brad has undertaken a number of pedagogical studies of engineering students regarding student approaches to learning, action learning and project-based education; the success of the educational initiatives associated with these studies have resulted in recognition through several teaching and learning awards. 
